\title{
Microstructural properties and fracture characteristics of friction stir welded joint for 2024 aluminum alloy
}

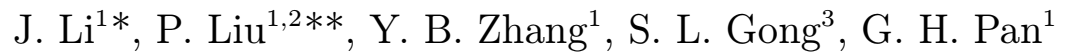 \\ ${ }^{1}$ School of Materials Science and Engineering, Shandong Jianzhu University, Jinan 250101, P. R. China \\ ${ }^{2}$ Key Laboratory for Advanced Materials Processing Technology Ministry of Education, \\ Department of Mechanical Engineering, Tsinghua University, Beijing 100084, P. R. China \\ ${ }^{3}$ Beijing Aeronautical Manufacturing Technology Research Institute, Beijing 100024, P. R. China
}

Received 26 May 2014, received in revised form 25 November 2014, accepted 1 December 2015

\begin{abstract}
The 2024 aluminum alloys with $3 \mathrm{~mm}$ thickness were welded successfully by friction stir welding (FSW). Microstructures and mechanical properties of joints were observed and analyzed. The test result indicated that the weld nugget zone was composed of refined and equiaxed grains. When the welding traveling speed is $300 \mathrm{~mm} \mathrm{~min}^{-1}$, the peak tensile strength of joints can reach to $294 \mathrm{MPa}$, as much as $70 \%$ of the value for the base materials. The fracture of the weld nugget zone is composed of equiaxed dimples with ductile fracture characteristics. Lots of the second phase particles, such as the $\mathrm{CuAl}_{2}$ phase, exist in the dimples. However, the upper shoulder affected zone shows the mixed fracture characteristic of cleavage and quasi-cleavage with little dimple. The fracture of the bottom swirl defects zone is a typical mixed fracture mode by the ductile and brittle fracture. The divisional structure of fracture is close related to the mechanical properties and microstructures of the FSW joint.
\end{abstract}

Ke y words: aluminum alloys, friction stir welding, defects

\section{Introduction}

Aluminum and aluminum alloys are widely used to obtain components for aerospace applications with high specific strength. However, heat-treatable aluminum alloys, such as $\mathrm{Al}-\mathrm{Cu}-\mathrm{Mg}, \mathrm{Al}-\mathrm{Mg}-\mathrm{Si}$ and $\mathrm{Al}-\mathrm{Zn}$, are often difficult to obtain the weld without hot cracking, porosity or distortions by conventional fusion welding techniques [1]. FSW is a recent method of joining materials, which constitutes a development of the classical friction welding methods [2]. During the FSW process, no melt of the joining parts occurs and the weld forms through solid-state plastic flow at elevated temperatures. FSW assures the absence of porosity, hot cracking and rather larger distortions that are typical defects of the fusion processes. Therefore, the FSW process can be used to weld heat-treatable aluminum alloys in order to obtain high-quality joints [3-5]. However, many studies on the microstructural characteristics and mechanical properties of the FSW joints indicate that FSW gives rise to softening in the joint of heat-treatable aluminum alloys because of the dissolution or growth of strengthening precipitates during the welding thermal cycle, thus resulting in the degradation of mechanical properties of the joints $[3,6-8]$. Hence, it is important to study the relation between mechanical properties and microstructure of FSW joints.

In this study, the 2024-T4 aluminum alloys were welded successfully by FSW. The microstructure, micro-hardness distribution, tensile strength and fracture characteristics of the friction stir welded joints were studied. This paper aims to demonstrate the relation between microstructural properties and fracture characteristics of joints. This study will provide an important basis for further studying microstructure of the friction stir welded joints, such as phase constituents, plastic flow and dislocations, etc. It is also favorable to determine the optimum welding parameters so as to obtain high-quality FSW joints.

*Corresponding author: e-mail address: jn2369@163.com

**Corresponding author: e-mail address: liupeng1286@163.com 
Ta ble 1. Chemical composition, thermo-physical and mechanical performance of 2024 aluminum alloy

\begin{tabular}{ccccccc}
\hline \multirow{7}{*}{ Material } & $\mathrm{Cu}$ & $\mathrm{Mg}$ & $\mathrm{Si}$ & $\mathrm{Fe}$ & $\mathrm{Mn}$ & other \\
\cline { 2 - 6 } $\mathrm{Al} 2024$ & $3.8-4.9$ & $1.2-1.8$ & 0.5 & 0.5 & $0.3-0.9$ & $\mathrm{Al}$ \\
\hline \multicolumn{7}{c}{ Thermo-physical and mechanical performance } \\
\hline $\begin{array}{c}\text { Density } \\
\left(\mathrm{g} \mathrm{cm}^{-3}\right)\end{array}$ & $\begin{array}{c}\text { Average specific heat volume } \\
\left(\mathrm{J} \mathrm{kg}^{-1} \mathrm{~K}^{-1}\right)\end{array}$ & $\begin{array}{c}\text { Heat conductivity } \\
\left(\mathrm{W} \mathrm{m}^{-1} \mathrm{~K}^{-1}\right)\end{array}$ & $\begin{array}{c}\text { Tensile strength } \\
(\mathrm{MPa})\end{array}$ & $\begin{array}{c}\text { Resistivity } \\
(\%)\end{array}$ & $\begin{array}{c}\text { Linear expansion factor } \\
\left(10^{-6} \mathrm{~K}^{-1}\right)\end{array}$ \\
\hline 2.77 & 875 & 120 & 425 & 57 & 24.7 \\
\hline
\end{tabular}

\section{Experiments}

The examined joined sheets of 2024-T4 aluminum alloys had dimensions of $150 \mathrm{~mm} \times 60 \mathrm{~mm} \times 3 \mathrm{~mm}$. The chemical composition, thermo-physical and mechanical performances of test material are shown in Table 1 . The two $3 \mathrm{~mm}$ thick sheets were butt welded by a FSW technique. The welding direction was parallel to the rolling direction of the sheets. The diameter of tool shoulder was $20 \mathrm{~mm}$, and that of tool pin was $6 \mathrm{~mm}$. The tool rotational speed and travel speed were $475 \mathrm{r} \mathrm{min}^{-1}$ and $150-375 \mathrm{~mm} \mathrm{~min}^{-1}$, respectively.

The 2024-T4 aluminum alloy sheets were welded successfully by FSW. A series of specimens was cut, and then these specimens were made into metallographic samples. The samples were etched using mixed solution $1.0 \% \mathrm{HF}+1.5 \% \mathrm{HCl}+2.5 \% \mathrm{HNO}_{3}+95 \%$ $\mathrm{H}_{2} \mathrm{O}$. The microstructure of stir zone was observed by optical microscopy. The micro-hardness tester of the MH-3 type was used to acquire micro-hardness distribution across the facing polished cross section with $100 \mathrm{~g}$ loading and a load time of $10 \mathrm{~s}$. The test of tensile strength for the friction stir welded joints was carried out on tensile test machine of the CSS1100 type. The fracture morphology of tensile joints was observed by means of scanning electron microscope (SEM) of S-450 type. During the SEM, the electron probe X-ray micro-analyzer (EPMA) was applied to measure the chemical composition of typical particle in the fracture.

\section{Results and analysis}

\subsection{Microstructural characteristics of the stir zone}

Figure 1a shows the macro image of FSW joints. There is no groove defect in the weld. The microstructure of the cross-section in the stir zone of joints is shown in Fig. 1b. It can be seen that the cross-section of joints was mainly composed of weld nugget zone (WNZ), thermo-mechanically affected zone (TMAZ) and heat affected zone (HAZ). However, some researchers also studied the microstructure of upper shoulder affected zone (SAZ) and bottom swirl defects zone (SDZ) $[9,10]$. According to Fig. 1a, there are no obvious welding voids or cracks in the cross-section of joints.

Figures $1 \mathrm{c}, \mathrm{d}$ show the microstructure of TMAZ and HAZ. The structure in weld nugget zone suffered from the thermo cycle of higher temperature because of the stir process by a tool pin. As a result, the structure in the stir zone experienced the dynamic recovery and dynamic recrystallization. However, the dynamic recovery course might be inhibited by a tool pin, such as the metal in WNZ. As a result, the metal in WNZ experienced a dynamic recrystallization course. The test results indicated that a fine equiaxed grain structure showed in the weld nugget zone (Fig. 1c). This structure is favorable to enhance the mechanical properties of the friction stir welded joints. Moreover, the subgrain structure, cellular structure and dislocations induced by dynamic recovery will decrease obviously.

According to Fig. 1d, there is an obvious boundary between WNZ and TMAZ. The metal in TMAZ also suffered from higher temperature, larger stress and strain, but the dynamic recrystallization phenomenon did not occur. However, the grains close to the weld nugget zone produced a larger tension and torsion by the tool pin, so those grains brought an obvious distortion along the tool pin direction (Fig. 1d). In this zone, the microstructure reflected directly the characteristic of the flowing materials during the FSW process.

\subsection{Mechanical properties of joints}

The micro-hardness of the stir zone of the friction stir welded joints for 2024 aluminum alloys was measured by means of the Shimadzu type microsclerometer, using $100 \mathrm{~g}$ loading and a load time of $10 \mathrm{~s}$. The test results are shown in Fig. 2. In Fig. 2a, the micro-hardness was measured from an advancing side (AS) to the retreating side (RS) along the weld cross section. The micro-hardness was also measured from the bottom swirl defects zone (SDZ) to the upper shoulder 

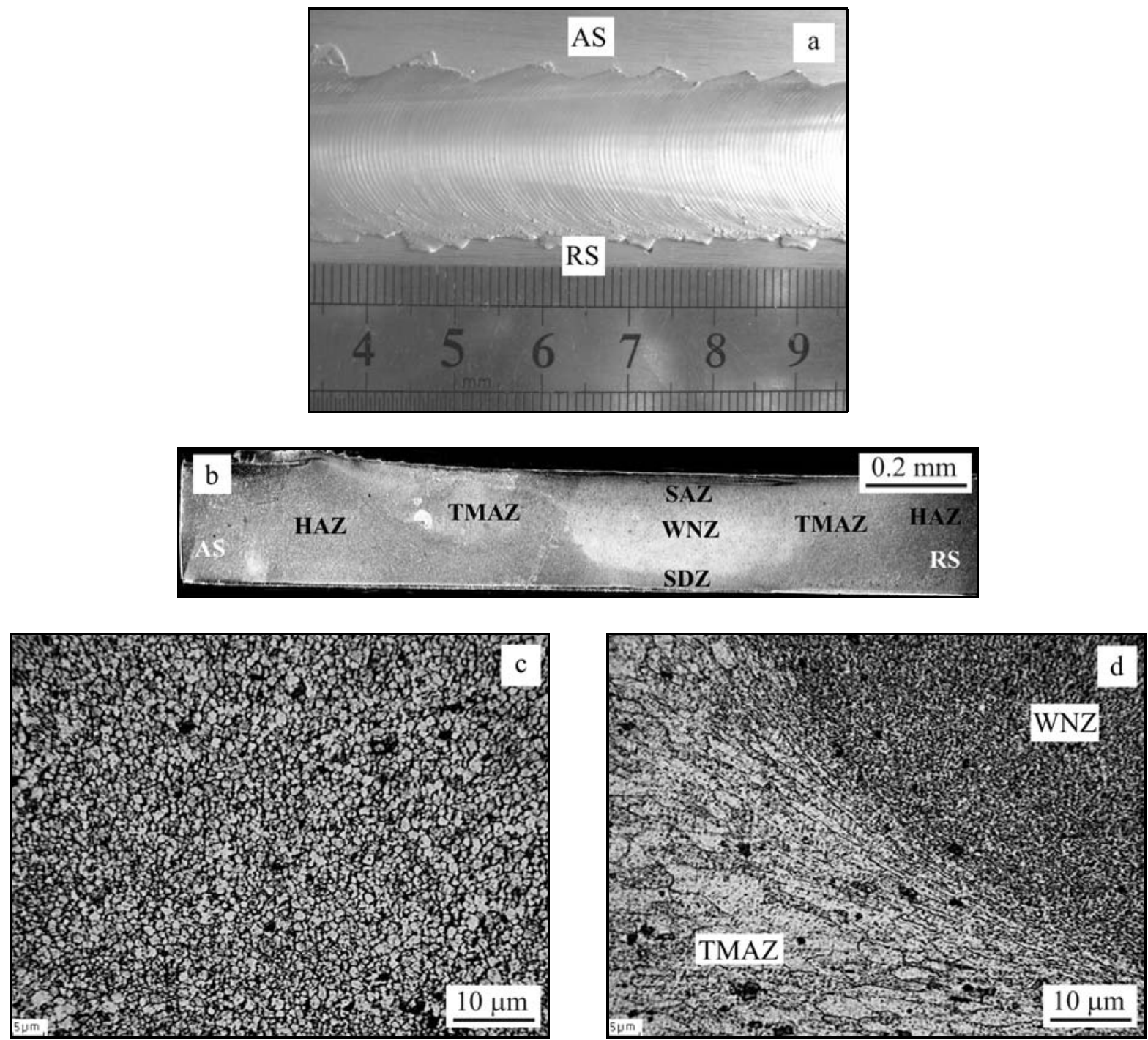

Fig. 1. Macro image of FSW joints (a), microstructure in the cross-section of joints (b), microstructure in WNZ (c), and the microstructure between TMAZ and WNZ (d).
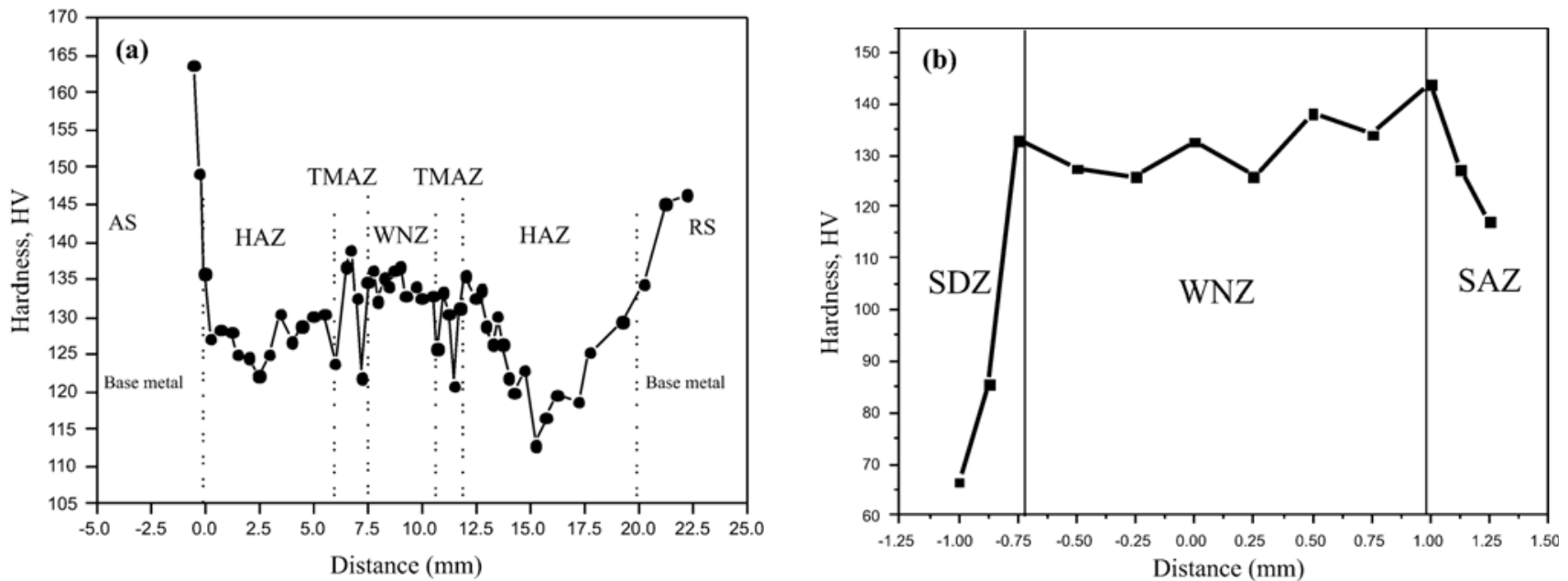

Fig. 2. Micro-hardness in the stir zone of FSW joints (a), and micro-hardness in WNZ, SDZ and SAZ (b). 

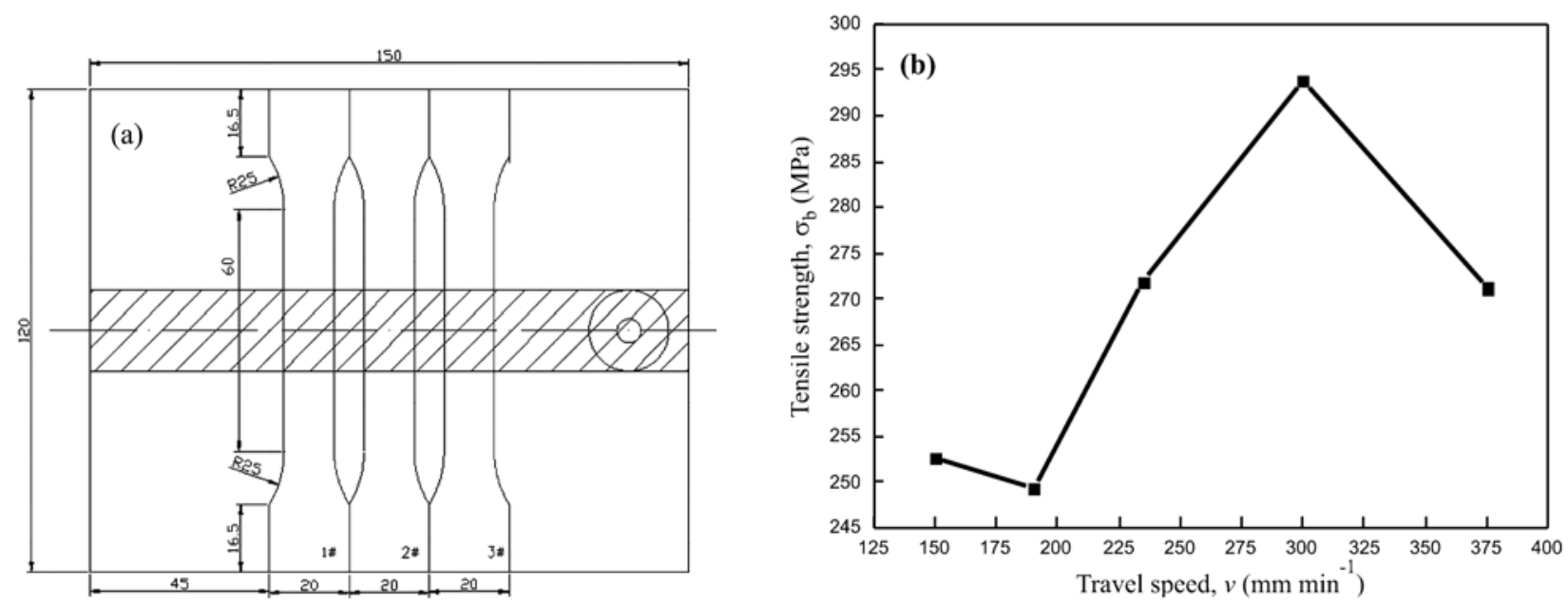

Fig. 3. Schematic of tensile test specimens (a), and the relation between tensile strength and travel speed of joints (b).

affected zone (SAZ) in Fig. 2b.

According to Fig. 2a, the hardness value from the base metal to weld zone decreased gradually. The hardness value was about HV120 in the HAZ. Then the hardness value toward the THAZ increased gradually, and reached to HV140. Finally, the hardness value decreased gradually in the WN. However, the micro-hardness distribution in this region was steady. The test results indicated that the hardness value near the interface of WNZ/TMAZ was quite approximate. However, the hardness value in the HAZ of two sides was obviously lower than in TMAZ. This difference was related to the growth and dissolution of some precipitated phases in this region [11-14]. This difference of the hardness distribution might induce a different shrinkage distortion of weld metal between HAZ and TMAZ during cooling. As a result, a larger residual stress concentration in this region will occur, making this region weaker of the hardness distribution for the FSW joints.

The micro-hardness distribution along the thickness direction of FS weld over the WNZ is shown in Fig. 2b. According to Fig. 2b, the hardness value of SDZ is lower than that of WNZ and SAZ. The welding temperature in this region was lower because the metal of SDZ was not directly contacted with the tool pin. However, the metal in this region produced plastic deformation as the tool pin rotated. Hence, no dynamic recrystallization was induced in this region.

The tensile test is an important target to reflect effectively mechanical properties of the friction stir welded joints for 2024 aluminum alloys. Figure 3 shows the dimensions of test specimens and test results for the tensile strength. According to Fig. 3b, the tensile strength of joints increased gradually with the increase of welding travel speed. When the welding travel speed was $300 \mathrm{~mm} \mathrm{~min}^{-1}$, the tensile strength could reach the maximum value of $294 \mathrm{MPa}$. It is about $70 \%$ of the tensile strength for 2024 aluminum alloys. However, with further increase of welding travel speed, the tensile strength of joints decreased gradually. The tensile strength of joints was about $60 \%$ of the value for 2024 aluminum alloys when the welding travel speed was $190 \mathrm{~mm} \mathrm{~min}^{-1}$.

\subsection{Fracture characteristics of tensile joints}

Fracture characteristics of tensile joints were observed by means of SEM in order to further analyze the mechanical properties of FSW joints. In this experiment, the tensile joint with maximum tensile strength was selected. The typical fracture morphologies of joints are shown in Fig. 4a. The joints of friction stir processed 2024 aluminum alloys were all fractured between HAZ and TMAZ in the retreating side (RS). The macro fracture morphology shows a smooth surface characteristics, and there is little fibrous structure in local area (Fig. 4a). The macro fracture shows an obvious divisional structure. According to microstructural analysis of the stir zone, the fracture was composed of weld nugget zone (WNZ), upper shoulder affected zone (SAZ) and bottom swirl defects zone (SDZ); moreover, a larger region in the middle of fracture shows the WNZ.

Figure $4 \mathrm{~b}$ shows the micro fracture morphology of WNZ. There were a large number of equiaxed dimples in the stir zone, so the fracture shows a characteristics of obvious ductile fracture. A large number of second phase particles exist in the dimples. These particles were analyzed by means of EPMA experiment. The test results indicate that these second phase particles may be $\mathrm{CuAl}_{2}$ phase. Chemical composition of a typical second phase particle is shown in Fig. 4f. The dimples and second phase particles existing in the WNZ indicated that this region had a high plastic deformability.

According to tensile test results, the maximum value of tensile strength is only $70 \%$ of the value 

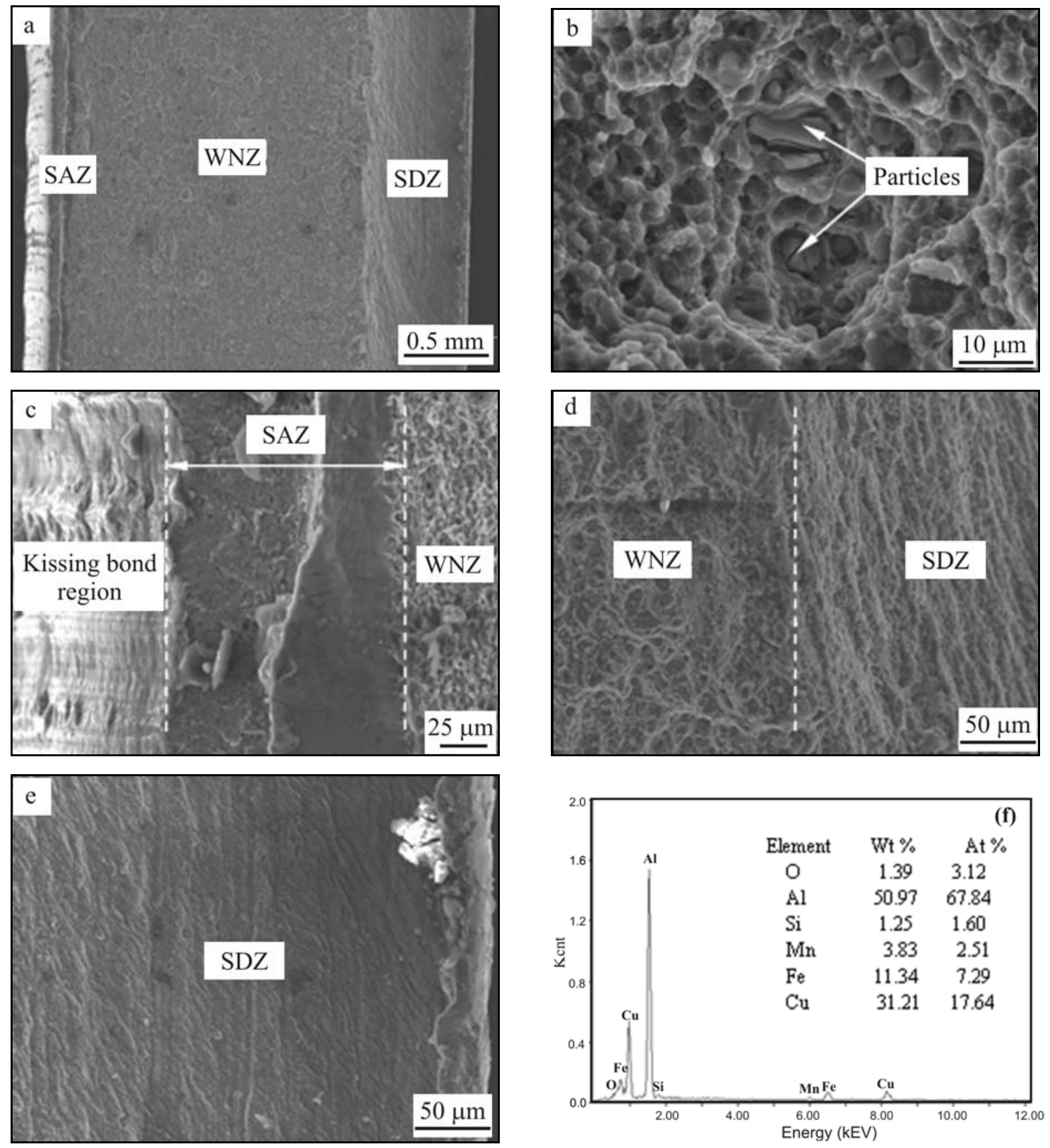

Fig. 4. Macro fracture morphology of FSW joints (a), fracture morphology of WNZ (b), fracture morphology of SAZ (c), fracture morphology of SDZ (d), (e), and EPMA results of second phase particles in Fig. 4b (f).

of base materials, which indicates that the fracture characteristics of SAZ and SDZ also has an important effect on the mechanical properties of FSW joints besides the fracture of WNZ. The fracture morphology of SAZ and SDZ is shown in Figs. 4c-e, respectively. The SAZ shows a fracture characteristics of cleavage and quasi-cleavage with little dimple. Therefore, the fracture of this region has an obvious brittle fracture characteristics (Fig. 4c). The fracture in the SDZ of fracture near the WNZ shows a characteristics of fibrous little elongated dimples. Compared with
WNZ, there is almost no second phase particle in the dimple (Fig. 4d). However, the fracture in the SAZ near the base materials shows an obvious cleavage fracture characteristics (Fig. 4e). As a result, the fracture of SDZ is a typical mixed fracture mode by the ductile and brittle fracture.

Note that an special region called kissing-bond region was observed in the left of SAZ. According to microstructural observation, this region is the surface metal of weld zone (Fig. 1a). This region was considered as the initial position of fracture [15]. How- 
ever, it can be seen that the interlayer spacing is about $0.08 \mathrm{~mm}$. Hence, the kissing-bond is extremely difficult to detect with any non-destructive testing method due to its sub-millimeter size.

The test results indicate that there are close relations among the tensile strength, micro-hardness and fracture characteristics of friction stir welded joints. According to the results of tensile strength, the tensile strength of joints is only $70 \%$ of the value of base materials (Fig. 3b). This indicates that the structure characteristics of SAZ and SDZ possibly plays an important role for the tensile test of joints. Although the effective area of WNZ with high plastic deformability is rather large during the tensile load, the SAZ and SDZ with brittle fracture characteristics will be a potential fracture origin of joints. As a result, the divisional structure of fracture will play an important effect on enhanced mechanical properties of joints.

The divisional structure of fracture in FSW joints is related to the role of the tool pin and welding thermal cycle of metal welded. During FSW, the metal in SAZ and WNZ both experienced plastic deformation by the tool pin. However, the metal in SAZ directly experienced the hydraulic pressure of the tool shoulder after the tool pin was inserted into base materials. Since the metal in this region directly contacted the air, the metal was cooled rapidly. As a result, the plastic deformation in this region might show an obvious dynamic recovery characteristics. Hence, this region will become a softening region of joints. For example, the micro-hardness in SAZ shows lower value (Fig. 2b). And the metal in this region will also produce a series of structural change, such as the forming dislocations, cellular structure and subgrain structure. For the SDZ, the metal near the WNZ indirectly experiences the effect of tool pin, so some structure of this region might be similar to WNZ. For example, the fracture with fibrous little elongated dimple shows in this region (Fig. 4d). However, the metal away from WNZ in the SDZ contacted with clamping fixture, so the metal was also cooled rapidly. As a result, this region might be rather complex softening structure yet. It can be seen that the micro-hardness value in this region is much lower than the zone of WNZ or SAZ (Fig. 2b). According to Fig. 4e, the fracture in this region shows an obvious cleavage fracture characteristics.

\section{Conclusions}

The 2024 aluminum alloys with $3 \mathrm{~mm}$ thickness were welded successfully by FSW. The microstructure analysis indicated that the structure in WNZ produced the dynamic recrystallization. The WNZ was composed of refined/equiaxed grains. The grains in the TMAZ close to WNZ produced larger tension and torsion, so those grains brought an obvious distortion along a direction of the tool pin.

The test results indicate that the hardness value near the interface of WNZ/TMAZ is quite approximate. However, the hardness value in the HAZ of two sides was obviously lower than in the TMAZ. For micro-hardness along the thickness direction of FS weld, the hardness value of the bottom swirl defects zone (SDZ) is lower than the zone of the WNZ and upper shoulder affected zone (SAZ). Tensile strength of joints increased gradually with the increase of welding travel speed. When the welding travel speed was $300 \mathrm{~mm} \mathrm{~min}^{-1}$, the tensile strength can reach to the maximal value $294 \mathrm{MPa}$. It is about $70 \%$ of tensile strength for 2024 aluminum alloys.

The macro fracture of FSW joints shows an obvious divisional structure. There were a large number of equiaxed dimples in WNZ. Some second phase particles (maybe $\mathrm{CuAl}_{2}$ phase) existed in the dimples. The fracture of WNZ shows a characteristics of the ductile fracture. However, the SAZ shows a fracture characteristics of cleavage and quasi-cleavage with little dimple. And the fracture of SDZ is a typical mixed fracture mode by ductile and brittle fracture. The fracture characteristics is close related to the mechanical properties and microstructure of the FSW joints.

\section{Acknowledgements}

This work was supported by the National Natural Science Foundation of China (Grant No. 51305240).

\section{References}

[1] Olea, C. A. W., Roldo, L., Strohaecker, T. R., dos Santos, J. F.: Welding in the World, 50, 2006, p. 78. doi:10.1007/BF03263464

[2] Sik, A.: Kovove Mater., 51, 2013, p. 197.

[3] Murr, L. E., Li, Y., Trillo, E. A., McClure, J. C.: Mater. Technol., 15, 2000, p. 37.

[4] Sato, Y. S., Kokawa, H., Enomoto, M.: Metall. Mater. Trans. A, 30, 1999, p. 2429. doi:10.1007/s11661-999-0251-1

[5] Ipekoglu, G., Erim, S., Goren, B., Kiral, G.: CAM, 51, 2013, p. 155.

[6] Benavides, S., Li, Y., Murr, L. E., Brown, D., McClure, J. C.: Scripta Mater., 41, 1999, p. 809. doi:10.1016/S1359-6462(99)00226-2

[7] Sato, Y. S., Kokawa, H.: Metall. Mater. Trans. A, 32, 2001, p. 3023. doi:10.1007/s11661-001-0177-8

[8] Liu, G., Murr, L. E., Niou, C. S., McClure, J. C., Vega, F. R.: Scripta Mater., 37, 1997, p. 355. doi:10.1016/S1359-6462(97)00093-6

[9] Fratini, L., Buffa, G., Palmeri, D., Hua, J., Shivpuri, R.: J. Eng. Mater. Tech., 128, 2006, p. 428. $\underline{\text { doi: } 10.1115 / 1.2204946}$ 
[10] Zhao, Y. H., Lin, S. B., Shen, J. J., Wu, L.: J. Aero. Mater., 26, 2006, p. 67 (in Chinese).

[11] Sato, Y. S., Park, S. H. C., Kokawa, H.: Metall. Mater. Trans. A, 32, 2001, p. 3033. doi:10.1007/s11661-001-0178-7

[12] Jones, P. M., Heurtier, J., Desrayaud, C., Montheilet, F., Allehaux, D., Driver, J. H.: Scripta Mater., 52, 2005, p. 693. doi:10.1016/j.scriptamat.2004.12.027

[13] Genevois, C., Deschamps, A., Denquin, A., DoisneauCottignies, B.: Acta Mater., 53, 2005, p. 2447. doi:10.1016/j.actamat.2005.02.007
[14] Genevois, C., Deschamps, A., Vacher, P.: Mater. Sci. Eng. A, 415, 2006, p. 162.

doi:10.1016/j.msea.2005.09.032

[15] Chen, H. B., Yan, K., Lin, T., Chen, S. B., Jiang, C. Y., Zhao, Y.: Mater. Sci. Eng. A, 433, 2006, p. 64. $\underline{\text { doi:10.1016/j.msea.2006.06.056 }}$ 